\title{
Immunohistochemical assessment of estrogen, progesterone receptors and HER2/neu overexpression by core needle biopsy in a sample of Iraqi breast cancer patients
}

\author{
Dahlia Raouf Mohammed, ${ }^{1}$ Nada A.S. Alwan, ${ }^{2}$ and Raji Hussein? \\ 'Medical City, Ministry of Health, Baghdad, Iraq. \\ ${ }^{2}$ National Cancer Research Center, University of Baghdad, Baghdad, Iraq. \\ Correspondence to Nada A.S. Alwan (email: nadalwan@yahoo.com). \\ (Submitted: 18 April 2019 - Revised version received:04 May 2019 - Accepted: 25 May 2019 - Published online: 26 August 2019)
}

\begin{abstract}
Objective The aim of this study was to assess ER, PR and Human Epidermal Growth Factor Receptor 2 (HER2)/neu expression in the specimens obtained by core needle biopsies (CNB) and to correlate the findings with some clinicopathological parameters such as (age, family history, side of breast lump, histological type and grade).

Methods This cross-sectional study was conducted on 62 female patients complaining of palpable breast lumps. All were subjected to the triple assessment test. Patients with mammography or ultrasonography results signifying BI-RADS 4 or 5 were selected for CNB using freehand automated gun instrument. Twenty-three out of 52 malignant cases (44.2\%) were with positive scores for ER. Twenty-six (50\%) of cases were positive regarding PR expression. HER2/neu overexpression revealed positive scores in 22 cases (42.3\%).

Results The correlation between expression of ER, PR and HER2/neu with family history, the side of breast lump and pathological type of carcinoma were statistically not significant. On the other hand, a significant correlation was noted between HER2/neu expression and women's age; the positive expression was more demonstrated among younger aged women (mean age 45 year), nevertheless, this correlation was not significant with ER, PR expression. Significant correlation was also found between HER2/neu overexpression in breast cancer specimens and the histopathological grading, while that association was not maintained for ER and PR expression.

Conclusion Immunohistochemical assessment of hormone receptors and HER2/neu expression in specimens of breast cancer tissues obtained by CNB technique can indicate tumor aggressiveness and further need for neoadjuvant therapy before surgical intervention.

Keywords core needle biopsy, estrogen, progesterone, HER2/neu, immunohistochemistry
\end{abstract}

\section{Introduction}

Breast cancer is the leading cause of cancer death among females in developing countries. ${ }^{1}$ In Iraq, it is the most common registered cancer among the society and the main cause of cancer related death among women. ${ }^{2}$ Previous Iraqi studies showed clearly that the disease usually affect middle age females and present relatively at late stages. ${ }^{3-6}$ Reproductive hormones are thought to influence breast cancer risk by increasing cell proliferation, thereby increasing the likelihood of DNA damage, as well as promotion of cancer growth.

Earlier studies suggest that reproductive patterns are more strongly associated with risk of hormone receptor-positive breast cancer compared with triple-negative breast cancer. ${ }^{8,9}$ Human epidermal growth factor receptor 2 (HER2) is a member of the epidermal growth factor receptor (EGFR/ErbB) family. Amplification or over-expression of the ERBB2 gene occurs in approximately $30 \%$ of breast cancers and is associated with increased disease recurrence and a worse prognosis. ${ }^{10}$ Signaling through the ErbB family of receptors promotes cell proliferation and opposes apoptosis, and therefore must be tightly regulated to prevent uncontrolled cell growth. ${ }^{1}$

Core needle biopsy (CNB), also called Tru-cut biopsy, is widely accepted in routine assessment for the diagnosis of breast cancer. It is a reliable method for histological diagnosis and it provides enough material to allow determination for additional markers such ER, PR and HER2 status. Those analyses are critical due to their implications in the guidance of clinical adjuvant proposal.
The aim of this study is to assess ER, PR and HER2/neu expression in specimens obtained by CNB from a sample of Iraqi breast cancer patients and to correlate the findings with some clinicopathological parameters including age, family history, side of breast lump, histological type and grade.

\section{Patients, Materials and Methods}

This cross-sectional study was conducted at the Main Referral Centre for Early Detection of Breast Tumors, Medical City, Baghdad and the Iraqi National Cancer Research Centre, Baghdad University. Sixty-two female patients complaining of palpable breast lumps were included in this study. All were subjected to the triple assessment test with physical examination, imaging (mammography and/or ultrasonography) and FNA. Patient with mammography or ultrasonography results signifying BI-RADS 4 or 5 were selected for CNB using freehand automated gun instrument (Bard Mgnum Biopsy Instrument).

At least 2-6 cores were obtained and the specimens were processed and stained with H\&E stain for histopathological evaluation. That was followed by further staining with IHC markers ER, PR and HER2/neu. Scoring was based on the examination of all tumor cells on the slide according to Allred scoring guideline for ER and PR. A proportion score (PS) was estimated through assessment of proportion of tumor cells with positive nuclear staining and includes five grades. An intensity score (IS) was estimated by average staining intensity of all positive tumor cells and includes four grades. A total 
score (TS) equal to sum of PS and IS. A positive result for both ER and PR is defined as TS $\geq 3$. Weak positivity (score $3-4$ ). Moderate positivity (score 5-6).

Strong positivity (score 7-8). Scoring of the IHC staining for HER2/neu overexpression was according to ASCO/CAP (Hercep test).

Statistical analyses of all results were performed utilizing SPSS software statistical package (version 18) using $t$-test and Chi-square. $P$-value at level of significance $<0.05$ was used to assess the correlation with some clinicopathological parameters.

\section{Results}

This study showed that the peak frequency of breast carcinoma occurred in the age group of 40-49 years. The mean age was $50+$ years old. There was an even distribution of breast carcinoma masses in right and left breast (48\% and 52\%) respectively. About $20 \%$ showed positive family history while $80 \%$ were with negative family history for breast cancer. Out of total 62 patients, malignant histopathological changes (B5) were displayed in $52(83.9 \%)$ patients, while the remaining 10 (16.1\%) patients where non-malignant (i.e., B1, B2, B3 and B4) as diagnosed by CNB technique. Lobular type has been identified in (17.8\%) while forty-one cases $(78.8 \%)$ were IDC in CNB. More than two-third of cases (68\%) of IDC by CNB were of grade II.

Twenty-three out of 52 malignant cases (44.2\%) were with positive scores for ER, 29 cases (55.8\%) were with negative scores. Equal numbers 26 (50\%) of cases for positive and negative scores regarding PR expression. HER2/neu overexpression revealed positive scores in 22 cases $(42.3 \%)$ while negative scores in the remaining 30 cases (57.7\%). Regarding the strength of expression for estrogen and progesterone receptors, the highest number of cases with positive scores for ER receptors showed weak positivity while the highest number with $\mathrm{PR}$ receptor score revealed strong positivity.

The correlation between expression of ER, PR and HER2/ neu with family history, the side of breast lump and pathological type of carcinoma were statistically not significant. A significant correlation was noted between HER2/neu expression and women's age; the positive expression was more among younger aged women (mean age 45 years), on the other hand this correlation was not significant with ER, PR expression (Table 1).

Regarding the correlation with histological type of malignancy; ER PR and HER2/neu receptors expression showed a non-significant statistical correlation with both types (i.e., ductal and lobular carcinoma) for 50 out of 52 malignant cases (as it was not possible to classify two cases by core biopsy diagnosis) as illustrated in Table 2.

While this correlation was not significant with ER and PR expression, as in Table 3.

\section{Discussion}

This Iraqi study focuses on immunohistochemical staining for CNB specimens and their correlation with clinicopathological data. Previous studies from the western societies and Iraq showed that the positive expression of ER and PR was increasing with age. ${ }^{12-14}$ In an Iraqi survey, the rates of the positive ER and PR and HER2 breast cancers were 67.8\%, 65.3\% and $29.4 \%$ respectively. ${ }^{14}$

\begin{tabular}{lccccc}
\hline $\begin{array}{l}\text { Table 1. Distribution of expression of ER, PR, and } \\
\text { HER2/neu with respect to age of the patients }\end{array}$ \\
$\begin{array}{l}\text { Receptor } \\
\text { expression }\end{array}$ & $\begin{array}{c}\text { Mean } \\
\text { age }\end{array}$ & SD* & t-Test & Df** & P-value \\
\hline ER +ve & 49.5 & 11.7 & 0.51 & 50 & 0.61 \\
ER -ve & 51.1 & 11.6 & & & \\
PR +ve & 51.2 & 11.02 & 0.44 & 50 & 0.66 \\
PR -ve & 49.8 & 12.2 & & & \\
HER2/neu +ve & 45.7 & 10.1 & 2.72 & 50 & 0.009 \\
HER2/neu -ve & 54 & 11.4 & & & \\
\hline
\end{tabular}

${ }^{*} \mathrm{SD}=$ standard deviation. ${ }^{*} \mathrm{D} f=$ degree of freedom.

"Highly significant.

\section{Table 2. Distribution of receptors according to the type of} mammary carcinoma

\begin{tabular}{|c|c|c|c|c|c|}
\hline $\begin{array}{l}\text { Receptor } \\
\text { expression }\end{array}$ & $\begin{array}{c}\text { Ductal } \\
\text { Ca }\end{array}$ & $\begin{array}{l}\text { Lobular } \\
\text { Ca }\end{array}$ & $\begin{array}{l}\text { Odds } \\
\text { ratio }\end{array}$ & $\begin{array}{l}\text { Confidence } \\
\text { interval }\end{array}$ & $P$-value \\
\hline$E R+v e$ & 18 & 5 & 0.25 & $0.05-1.39$ & 0.4 \\
\hline ER -ve & 23 & 4 & & & \\
\hline$P R+v e$ & 19 & 5 & 0.76 & $0.18-3.26$ & 0.71 \\
\hline$P R$-ve & 20 & 4 & & & \\
\hline HER2/neu +ve & 19 & 2 & 3.02 & $0.56-16.33$ & 0.18 \\
\hline HER2/neu -ve & 22 & 7 & & & \\
\hline
\end{tabular}

Significant correlation was also found between HER2/neu overexpression in breast cancer specimens and the histopathological grading.

\begin{tabular}{|c|c|c|c|c|}
\hline $\begin{array}{l}\text { Receptor } \\
\text { expression }\end{array}$ & $\begin{array}{l}\text { Grade I } \\
(n=3)(\%)\end{array}$ & $\begin{array}{l}\text { Grade II } \\
(n=33)(\%)\end{array}$ & $\begin{array}{l}\text { Grade III } \\
(n=14)(\%)\end{array}$ & $P$-value \\
\hline$E R+v e$ & $3(100)$ & $14(42.4)$ & $4(28.6)$ & 0.3 \\
\hline ER -ve & $0(0)$ & 19 (57.6) & $10(64.3)$ & \\
\hline$P R+v e$ & $3(100)$ & $16(48.5)$ & $5(35.7)$ & 0.28 \\
\hline PR -ve & $0(0)$ & $17(51.5)$ & $9(64.3)$ & \\
\hline $\begin{array}{l}\text { HER2/neu } \\
\text { +ve }\end{array}$ & $0(0)$ & $12(36.4)$ & $9(64.3)$ & $0.047^{*}$ \\
\hline $\begin{array}{l}\text { HER2/neu } \\
\text {-ve }\end{array}$ & $3(100)$ & 21 (63.6) & $5(35.7)$ & \\
\hline
\end{tabular}

*Significant.

The difference in the results of the IHC staining among different studies from the same region might be due to technical variations due to the use of different manufacturers and various kits. In the current study, however, no significant association between ER, PR and age was displayed, probably due to the lower number of cases included. On the other hand, a significant correlation was found between HER2/neu overexpression and women's age; the positive expression was more demonstrated among younger aged women (i.e., below 50 year), reflecting the more aggressive behavior of mammary carcinoma in young women.

The correlation of family history with the expression of ER, PR, and HER2/neu was not statistically significant. Studies 
suggest an ethnic and racial difference between communities regarding the impact of family history of breast cancer on the expression of hormonal receptors. ${ }^{15,16}$ An Iraqi study carried out to illustrate the clinicopathological features of patients with positive family history of breast cancer revealed that the peak age frequency at the time of diagnosing breast cancer among those patients was in the fifth decade of life; illustrating no distinct correlation for their identification.

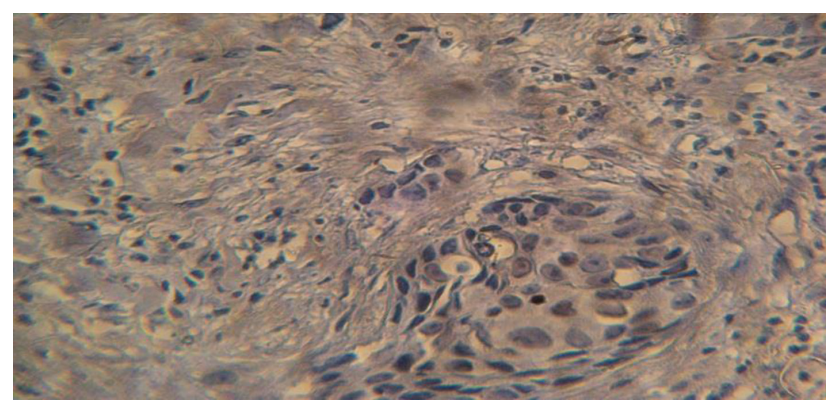

Fig. 1 Immunohistochemical stain for estrogen receptors in invasive ductal carcinoma. Nuclear brown positive staining of tumor cells against a negative cytoplasmic and stromal background. The total score is 5 (moderate positivity) $(40 x+3.0 x)$.

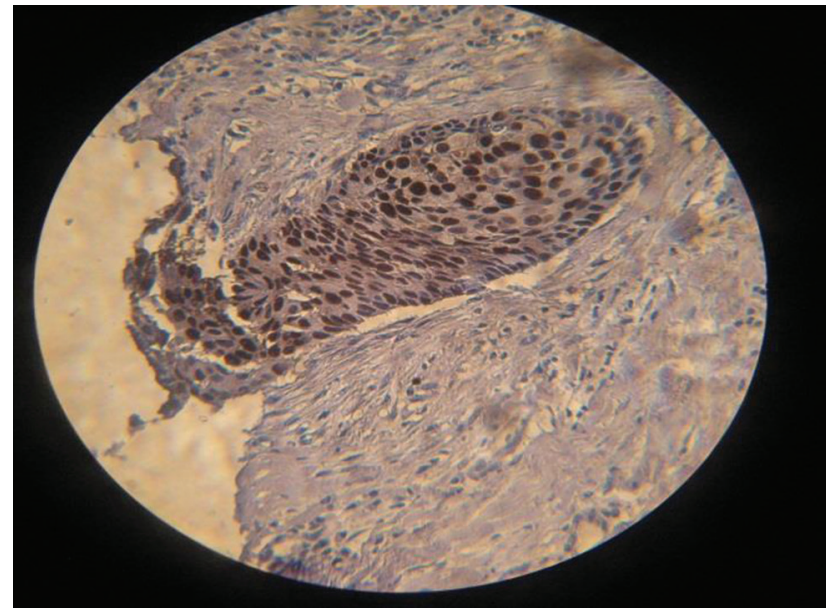

Fig. 2 Immunohistochemical stain for progesterone receptors in invasive ductal carcinoma. Strong nuclear positivity of tumor cells against a negative cytoplasmic and stromal background. Total score is 8 (strong positivity) (40X).

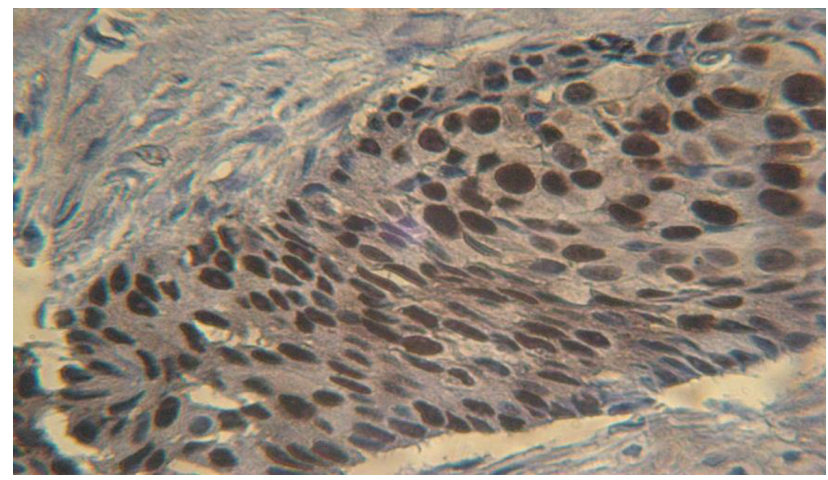

Fig. 3 Immunohistochemical stain for progesterone receptors in invasive ductal carcinoma. Strong nuclear positivity of tumor cells against a negative cytoplasmic and stromal background. Total score is 8 (strong positivity) $(40 x+3.0 x)$.

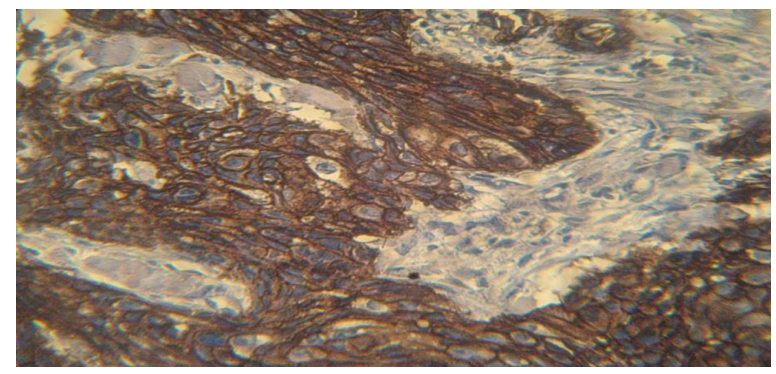

Fig. 4 Strong (3+) membrane immunoreactivity for HER2/neu. A complete membrane staining and strong intensity of more than $30 \%$ of tumor cells $(40 x+3.0 x)$.

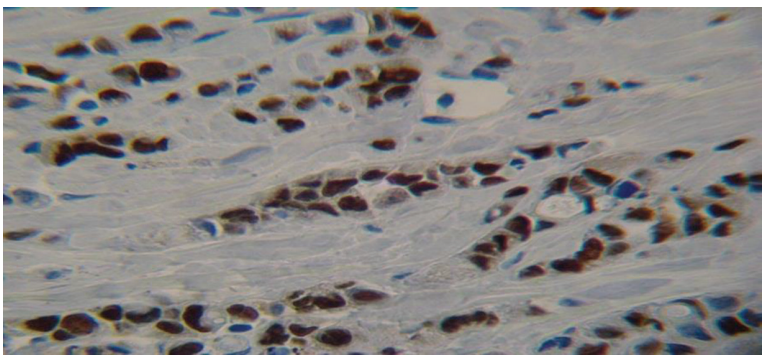

Fig. 5 HER2/neu score 1+ (negative) incomplete membrane immunoreactivity and faint staining in more than $10 \%$ of tumor cells $(40 x+3.0 x)$.

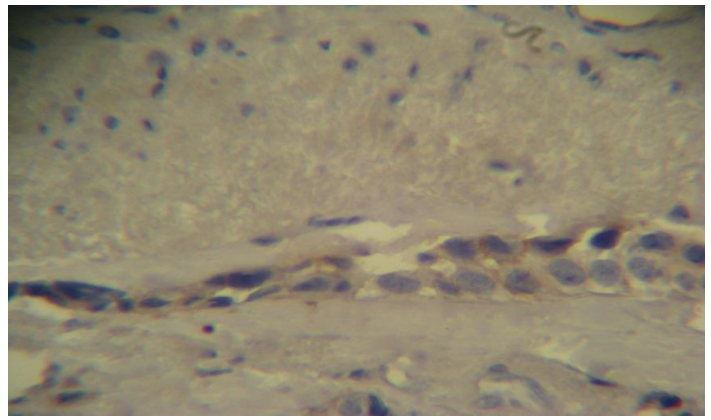

Fig. 6 Infiltrative lobular carcinoma showed strong nuclear positivity for progesterone receptors $(40 x+3.0 x)$.

In this study as well no significant correlation was noted regarding the correlation of ER, PR or HER2/neu with the type of mammary carcinoma. While both progesterone and estrogen receptors did not show any significant correlation with histopathological grading of breast cancer, HER2/neu receptors over expression revealed a significant association. The more the aggressive the tumor was, the more likelihood HER2/neu expression being positive. Similar findings were noted in other local studies. ${ }^{12-14}$

A recent meta-analysis has shown that the CNB tissue could replace open excision biopsy for determining ER, PR, and HER2 status. ${ }^{18}$ The 2015 European Society of Medical Oncology breast cancer clinical practice guideline recommends a preoperative pathological examination of the $\mathrm{CNB}$, with a report on ER, PR, and HER2 status by IHC or fluorescence in situ hybridization. ${ }^{19}$ Similar to previous single center studies, ${ }^{20}$ the results is subject for selection bias. Some patients were initially diagnosed in other institutes and referred to the surgical department. In those cases, $\mathrm{CNB}$ was not reexamined, except in cases of vague diagnoses. 


\section{Conclusion}

Immunohistochemical staining are readily assessed for hormone receptors and HER2/neu expression in specimens of breast cancer tissues obtained by CNB technique to document tumor aggressiveness and the further need for neoadjuvant therapy. Significant correlations were demonstrated between HER2/neu expression and the age of the patients; higher positive scores were displayed among younger women. Likewise, a statistical association was noted between HER2/neu over expression in breast cancer specimens and the histopathological grading._Nevertheless, no significant correlation was shown between the expressions of ER, PR and HER2/neu and the side of the affected breast, the family history and the histopathological type.

\section{Recommendations}

Further study with larger sample size is recommended to correlate the IHC expression as prognostic and predictive markers in $\mathrm{CNB}$ and their significance with clinicopathological parameters and to follow up the patients response to adjuvant therapy.

\section{Acknowledgments}

The authors would like to thank the staff at the Main Referral Centre for Early Detection of Breast Tumors, Medical City Teaching Hospital, Baghdad) and those working in the National Cancer Research Center of Baghdad University or their kind help and cooperation.

\section{References}

1. Bray F, Ferlay J, Soerjomataram I, Siegel RL, Torre LA, Jemal A. Global cancer statistics 2018: GLOBOCAN estimates of incidence and mortality worldwide for 36 cancers in 185 countries. Cancer J Clin. 2018;68:394-424.

2. Annual Report. Iraqi Cancer Registry 2016. Iraqi Cancer Board, Ministry of Health and Environment, Republic of Iraq; 2018.

3. Alwan NA. Breast cancer: demographic characteristics and clinicopathological presentation of patients in Iraq. East Mediterr Health J. 2010;16:1159-1164.

4. Alwan NAS, Tawfeeg F, Maallah M, Sattar SA, Saleh WA. The stage of breast cancer at the time of diagnosis: correlation with the clinicopathological findings among Iraqi patients. J Neoplasm 2017;2:1-10.

5. Alwan NAS. Breast cancer among Iraqi women: preliminary findings from a regional comparative breast cancer research project. J Glob Oncol. 2016;2:255-258.

6. Alwan NAS. Tumor characteristics of female breast cancer: pathological review of mastectomy specimens belonging to Iraqi patients. World J Breast Cancer Res. 2018;1:1-3.

7. Hulka BS, Moorman PG. Breast cancer: hormones and other risk factors. Maturitas 2001;38:103-113; discussion 113-116.

8. Eliassen AH, Missmer SA, Tworoger SS, Spiegelman D, Barbieri RL, Dowsett $\mathrm{M}$, et al. Endogenous steroid hormone concentrations and risk of breast cancer among premeno-pausal women. J Natl Cancer Inst. 2006;98:14061415.

9. Kaaks R, Berrino F, Key T, Rinaldi S, Dossus L, Biessy C, et al. Serum sex steroids in premeno-pausal women and breast cancer risk within the European Prospective Investigation into Cancer and Nutrition (EPIC). J Natl Cancer Inst. 2005:97:755-765.

10. Tan M, Yu D. Molecular mechanisms of erbB2-mediated breast cancer chemoresistance. Adv Exp Med Biol. 2007;608:119-129.

11. Roy V, Perez EA. Beyond trastuzumab: small molecule tyrosine kinase inhibitors in HER-2-positive breast cancer. Oncologist 2009;14:1061-1069.

12. Alwan NAS, Mualla F, Naqash M, Kathum S, Tawfiq FN, Nadhir S. Clinical and pathological characteristics of triple positive breast cancer among Iraqi patients. Gulf J Oncol. 2017;25:6-15

13. Alwan NAS, Kerr D, Al-Okati D, Pezella F, Tawfeeq F. Comparative study on the clinicopathological profiles of breast cancer among Iraqi and British patients. Open Public Health J. 2018;11:177-191.

14. Alwan NAS, Tawfeeg FN, Muallah FH. Breast cancer subtypes among Iraqi patients: identified by their ER, PR and HER2 status. J Fac Med Baghdad 2017:59:304-307.

15. Hines LM, Risendal B, Slattery ML, Baumgartner KB, Giuliano AR, Byers T. Differences in estrogen receptor subtype according to family history of breast cancer among Hispanic, but not non-Hispanic White women. Cancer Epidemiol Biomarkers Prev. 2008;17:2700-2706.

16. Jiang $X$, Castelao JE, Chavez-Uribe E, Fernandez Rodriguez B, Celeiro Muñoz C, Redondo CM, et al. Family history and breast cancer hormone receptor status in a Spanish cohort. PLoS One 2012;7:e29459.

17. Alwan NAS. Family history among Iraqi patents diagnosed with breast cancer. Int J Sci Res. 2017:6:868-872.

18. Chen X, Yuan Y, Gu Z, Shen K. Accuracy of estrogen receptor, progesterone receptor, and HER2 status between core needle and open excision biopsy in breast cancer: a meta-analysis. Breast Cancer Res Treat. 2012;134:957-967.

19. Senkus E, Kyriakides S, Ohno S, Penault-Llorca F, Poortmans P, Rutgers E et al. Primary breast cancer: ESMO Clinical Practice Guidelines for diagnosis, treatment and follow-up. Ann Oncol. 2015;26:v8-v30.

20. You K, Park S, Ryu JM, Kim I, Lee SK, Yu J, et al. Comparison of core needle biopsy and surgical specimens in determining intrinsic biological subtypes of breast cancer with immunohistochemistry. J Breast Cancer 2017:20:297-303. 